\title{
Effect of solution treatment on microstructures and mechanical properties of industrial 7050 thick plate
}

\author{
Zhiqiang Xie ${ }^{1}$, Zhihong Jia ${ }^{1,2,4^{*}}$, Lin Lin ${ }^{3}$, Shunyan $\operatorname{Lin}^{3}$, and Qing Liu ${ }^{1,4}$ \\ ${ }^{1}$ International Joint Laboratory for Light Alloys (Ministry of Education), College of Materials Science and Engineering, Chongqing \\ University, Chongqing 400044, China \\ ${ }^{2}$ Electron Microscopy Center of Chongqing University, Chongqing 400044, China \\ ${ }^{3}$ Southwest Aluminum (Group) Co., Ltd, Chongqing 401326, China \\ ${ }^{4}$ Key Laboratory for Light-weight Materials, Nanjing Tech University, Nanjing 210009, China
}

\begin{abstract}
In this work, effect of solution treatments on the microstructures and mechanical properties of industrial 7050 aluminum alloy thick plate was investigated by tensile test, scanning electron microscopy (SEM), energy dispersive spectrometry (EDS) and transmission electron microscopy (TEM). The results show that the area fraction of residual phases decreases with increasing solution temperature from $475^{\circ} \mathrm{C}$ to $500^{\circ} \mathrm{C}$. The overheating phenomenon identified by compound melting ball and crystal separating phase was observed at a temperature of $485^{\circ} \mathrm{C}$ or above. The compound melting balls are composed of $\mathrm{S}\left(\mathrm{Al}_{2} \mathrm{CuMg}\right)$ phase dissolved with $\mathrm{Zn}$ atoms and $\mathrm{Al}$ matrix. The crystal separating phase is consisted of $\mathrm{Al}_{2} \mathrm{Cu}$ phase and the amorphous structure containing solute atom $\mathrm{Mg}$. The maximum tensile strength of $529 \mathrm{MPa}$ was obtained for the alloy solution treated at $475^{\circ} \mathrm{C}$ for $3 \mathrm{~h}$ followed by peak aging at $120^{\circ} \mathrm{C}$ for $24 \mathrm{~h}$.
\end{abstract}

\section{Introduction}

The 7050 aluminum alloy thick plates have been widely used as structural components in aerospace industries due to good combination of the strength and toughness [1]. Therefore, a number of investigations have been carried out on the processes and microstructures of the 7050 aluminum alloy [2-5]. In order to obtain improved mechanical properties, the production of 7050 thick plates involves several heat treatment stages including homogenization, solutionizing, quenching and aging. Precipitation and/or dissolution of second phase particles occur during these heat treatment steps which have great influence on the microstructural evolution in subsequent stages. Generally, the solution treatment, an important step, is to re-dissolve the soluble phases formed during solidification into matrix as much as possible [6-8]. Thus, it is necessary to understand the relation between solution temperature and dissolution of second phases. This understanding is also critical in designing optimized process.

Typical soluble constituent phases in $\mathrm{Al}-\mathrm{Zn}-\mathrm{Mg}-\mathrm{Cu}$ $7 \mathrm{xxx}$ series aluminum alloys include $\mathrm{Mg}(\mathrm{Zn}, \mathrm{Mg}, \mathrm{Cu})_{2}$, $\mathrm{S}\left(\mathrm{Al}_{2} \mathrm{CuMg}\right)$ and $\mathrm{Al}_{2} \mathrm{Cu}$ phases. After homogenization treatment and thermomechanical processing, the resolvable residual phases are $\mathrm{Mg}(\mathrm{Zn}, \mathrm{Mg}, \mathrm{Cu})_{2}$, $\mathrm{S}\left(\mathrm{Al}_{2} \mathrm{CuMg}\right)[9,10]$. And these residual phases can degrade the effect of age-hardening and aid crack initiation and propagation. Additionally, these remnant phases can lead to micro-galvanic corrosion when the alloys are exposed to aqueous corrosive environments [11-13]. Therefore, an appropriate solution process is required to resolve as many residual phases as possible. The main factors for the solution treatment are temperature, holding time, and cooling rate. The effect of solution temperature is the most obvious. Increasing the solution temperature within a certain range can increase the solid solubility of solute atoms in the matrix, thereby the effect of solution treatment could be improved. The choice of solution temperature depends on the melting temperature of the low melting point residual phases. It has been reported that the melting temperatures associated with $\mathrm{Mg}(\mathrm{Zn}, \mathrm{Mg}, \mathrm{Cu})_{2}$ and $\mathrm{S}\left(\mathrm{Al}_{2} \mathrm{CuMg}\right)$ are about $475-478^{\circ} \mathrm{C}$ and $490-501^{\circ} \mathrm{C}$, respectively. It can be accepted that the soluble phase can re-dissolve more sufficiently at a higher solution temperature. But, excessive solution temperature will cause overheating of the alloy, which will seriously damage the microstructure and properties [14].

A large number of studies have been carried out on the effect of solution temperature on the microstructure and mechanical properties of 7050 aluminum alloys [15, 16]. The phenomenon of overheating has also been observed when a solution temperature is beyond a limited temperature in 7050 aluminum alloy. Generally, it has been widely accepted that the solution temperature for overheating is about $480^{\circ} \mathrm{C}$ for 7050 alloy. And the overheated characteristic structure takes on the compound melting ball, crystal separating phase and overheating triangle section. In addition, characteristic structure of overheating is changed with variant degree of overheating, and the mechanical properties also fail to change much when the alloy just started to overheat,

Corresponding author: zhihongjia@cqu.edu.cn.org 
while decrease fast with increasing a solution temperature causing overheating $[14,17,18]$.

Therefore, a suitable solution temperature can maximize to re-dissolve the residual phases, which has an important effect on obtaining good comprehensive mechanical properties. At the same time, understanding the effects of different degrees of overheating on the microstructure and mechanical properties of alloys can provide a reference for optimizing solid solution parameters. However, there are little researches focusing on basic characteristics of overheated structure and its influence on alloy properties. In this work, the effect of different solution temperatures on the microstructure and mechanical properties of 7050 alloy is investigated, including statistics of residual phases, phase evolution, and tensile properties testing. In particular, a variety of microanalysis methods are used to systematically study the microstructure of overheating.

\section{Experimental}

The current study was carried out on the $130 \mathrm{~mm}$ thick plate of the hot rolled 7050 aluminum alloy with chemical composition of Al-5.90\% Zn-2.10\% Mg-2.10\% $\mathrm{Cu}-0.11 \% \mathrm{Zr}-0.07 \% \mathrm{Fe}-0.03 \% \mathrm{Si}$ (wt.\%), which was provided by Southwest Aluminum (Group) Co., Ltd Chongqing, China. For the experiments, the $10 \times 10 \times$ $10-\mathrm{mm}^{3}$ specimens and the standard tensile specimens were cut from a quarter of the thick plate along the thickness direction. The dimension of tensile specimens is shown in Fig. 1. Samples were solution treated at $475^{\circ} \mathrm{C} / 3 \mathrm{~h}, \quad 485^{\circ} \mathrm{C} / 3 \mathrm{~h}, \quad 500^{\circ} \mathrm{C} / 3 \mathrm{~h}$, respectively. The solution treatments were carried out in air furnace, quenched in room temperature water and then aged at $120^{\circ} \mathrm{C}$ for $24 \mathrm{~h}$.

The microstructure of the alloy was characterized by scanning electronic microscopy (SEM) (AURIGA, Zeiss) and transmission electron microscopy (TECNAI F20, ThermoFisher) operated at $200 \mathrm{keV}$. Samples for microstructural observations by SEM were prepared by standard mechanical grinding and followed by suspension polishing. The composition and distribution of the residual phases were analyzed by SEM equipped with an energy-dispersive spectrometer detector (EDS) and back scatter electron detector (BSE). The TEM specimens of as-quenched samples were prepared by focused ion beam (FIB) thinning. The ambient temperature tensile tests were performed on a SHIMADZU AG-X 10KN universal testing machine at a tensile velocity of $3 \mathrm{~mm} / \mathrm{min}$, and the fractured surfaces were observed by SEM.

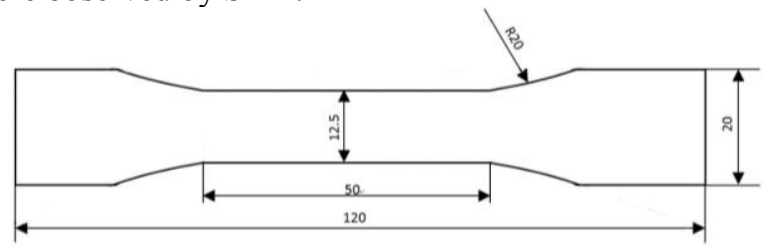

Fig. 1. The size of standard tensile specimen (unit: $\mathrm{mm}$ )

\section{Results and discussion}

Fig. 2 shows SEM micrographs of the hot rolled 7050 aluminum alloy solution treated at different conditions. residual phase particles are reduced graudally with increasing the solution temperature from $475^{\circ} \mathrm{C}$ to $500^{\circ} \mathrm{C}$, but they are still observed after solution treatment at $500^{\circ} \mathrm{C}$. In addition, the compound melting balls and overheating triangle sections are also observed in Fig. $2 b$ and Fig. 2c (inside the red ellipse), which belong to overheated characteristic structure. Ten SEM micrographs taken from the samples treated at each different solution temperature were analyzed by Image $\mathbf{J}$ to provide the area fraction and number density of the residual phases, and the statistical results are presented in Fig. 3. The number of residual phases gradually decrease with the increase of solution temperature as shown in Fig. 3a. And it can be seen from Fig. 3b that with the solution temperature increasing, the number density of the residual phases with the particle diameter less than $12 \mu \mathrm{m}$ gradually decreases, while increases when the particle diameter is greater than $12 \mu \mathrm{m}$.

It is well known that the more of the residual phase particles are re-dissolved, the better of the solid solution strengthening and subsequent aging strengthening are. However, the alloy sample has been obviously overheated when a solution temperature reached $485^{\circ} \mathrm{C}$ or above, indicating the applied temperature exceeding the melting temperature of some phases. According to the reported melting points of the constituent phases in the alloy, $\operatorname{Mg}(\mathrm{Zn}, \mathrm{Mg}, \mathrm{Cu})_{2}$ phase should be re-dissolved firstly when a solution temperature reaches $475^{\circ} \mathrm{C}$. With further increasing a solution temperature up to $485^{\circ} \mathrm{C}$ or above, the alloy has been overheated because the temperature has surpassed the melting point of the $\mathrm{Mg}(\mathrm{Zn}, \mathrm{Mg}, \mathrm{Cu})_{2}$ phase. The area fraction of residual phase will be even smaller at higher solution temperature, because in addition to complete dissolution of $\mathrm{Mg}(\mathrm{Zn}, \mathrm{Mg}, \mathrm{Cu})_{2}$ phase, some phase $\mathrm{S}$ phase particles will also start to re-dissolve [14]. At the same time, the compound melting balls produced by overheating have larger diameter, so that the number density of residual phase increases with increasing of solution temperature when the particle diameter is larger than $12 \mu \mathrm{m}$.

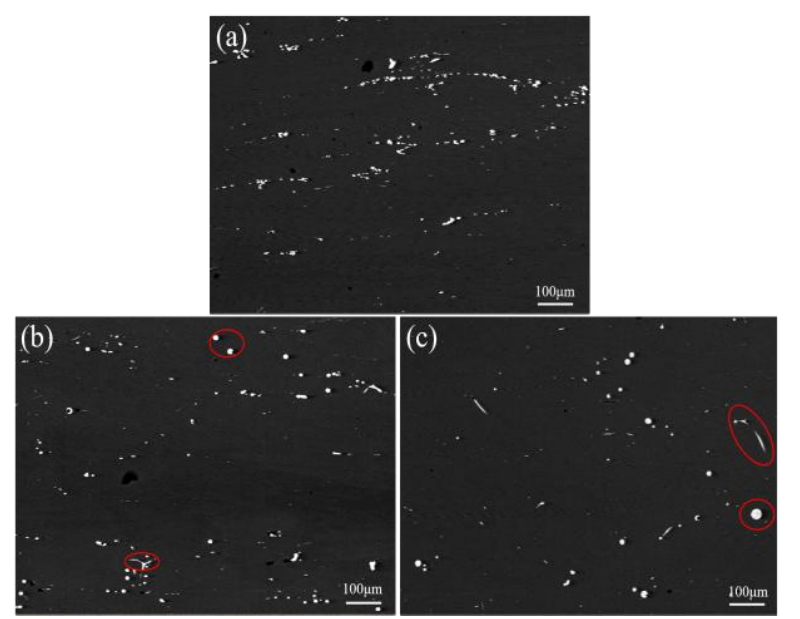

Fig. 2. SEM micrographs of the 7050 aluminum alloy solution treated at different conditions (a) $475^{\circ} \mathrm{C} / 3 \mathrm{~h}$, (b) $485^{\circ} \mathrm{C} / 3 \mathrm{~h}$, (c) $500^{\circ} \mathrm{C} / 3 \mathrm{~h}$. 

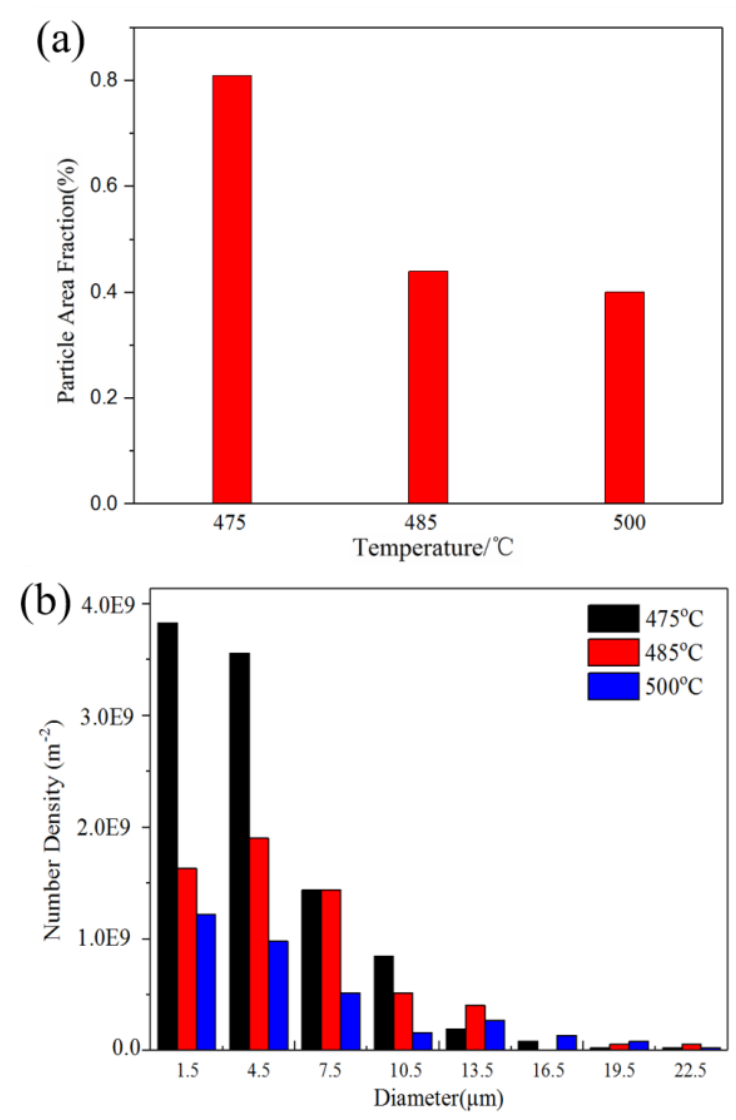

Fig. 3. The area fraction (a) and number density (b) of the residual phases in 7050 aluminum alloy solution treated at different conditions.

In order to systematically analyze the effect of solution temperature on microstructure, the evolution of residual phases were investigated in more detail. Fig. 4 shows SEM micrographs of the typical residual phases and the corresponding EDS mappings of the samples solution treated at different conditions. It can be seen that the main $\mathrm{S}\left(\mathrm{Al}_{2} \mathrm{CuMg}\right)$ phase is left in the alloy after solution treated at $475^{\circ} \mathrm{C} / 3 \mathrm{~h}$ and no overheating phenomenon is found. However, the compound melting balls are observed in the remained residual phases after solution treated at $485^{\circ} \mathrm{C} / 3 \mathrm{~h}$ or $500^{\circ} \mathrm{C} / 3 \mathrm{~h}$, indicating the occurrence of overheating. The compound melting ball has complex structure as revealed by different contrast through the ball. The EDS mappings in Fig. 4d and Fig. $4 \mathrm{f}$ reveal the $\mathrm{Zn}$ distribution besides $\mathrm{Al}, \mathrm{Mg}, \mathrm{Cu}$ compositions in this kind of compound melting ball. To understand the microstructure and structure of the ball, TEM investigations were done. The TEM sample of the interesting compound melting ball was prepared from the red-square marked area in Fig. 5a by focused ion beam (FIB). Two kinds of phases with different contrasts are observed clearly in Fig. 5c. The diffraction patterns of two phases in Fig. 5d and e reveal the compound melting ball composed of the S phase and the Al matrix, respectively. The EDS analysis from Fig. 5f and Fig. 5g shows that the $\mathrm{Zn}$ atoms in the compound melting ball mainly exist in the $\mathrm{S}$ phase.

Fig. 6 presents the crystal separating phase also belonging to the compound melting structure due to overheating. It can be further confirmed that the 7050 alloy has been overheated after solution treated at $485^{\circ} \mathrm{C} / 3 \mathrm{~h}$ or $500^{\circ} \mathrm{C} / 3 \mathrm{~h}$. Moreover, the TEM sample, prepared by FIB, was used to analyze the composition of crystal separating phase from the alloy after solution treated at $500^{\circ} \mathrm{C} / 3 \mathrm{~h}$ (Fig. $6 \mathrm{~b}$ yellow box area), and the results are shown in Fig. 7. It can be easily found from Fig. 7a that the crystal separating phase is not made up of one phase. The microstructure at position 1 is shown in Fig. 7b, indicating an amorphous structure. The diffraction spot at position 2 in Fig. $7 \mathrm{a}$ is shown in Fig. 7c. Combined with the energy spectrum information of Fig. 7 d, it can be determined that it is the $\mathrm{Al}_{2} \mathrm{Cu}$ phase at position 2 and the amorphous structure at position 1 containing the $\mathrm{Mg}$ solute atom.

Through the above micro-analysis, the compound melting ball and the crystal separating phase are typical overheating microstructure of the 7055 aluminum alloy. The main reason for forming the compound melting structure during overheating is that the solution temperature exceeds the melting temperature of the residual phase. When an overheating temperature is low, the low melting point phases are likely to be enriched at the grain boundary to form small compound melting pellets because of higher energy at the grain boundary. As an overheating temperature continues to rise, sufficient energy is obtained inside the grain and the compound melting balls also form in the gain besides at grain boundaries. With further increasing the overheating temperature, the compound melting balls evolve gradually and form a continuous compound structure at the grain boundaries. It is well known that overheating is detrimental to the comprehensive mechanical properties of the alloy. The compound melting balls with a large particle diameter and the crystal separating phase will cause stress concentration in the 7055 aluminum alloy. On the other hand, it can be seen from Fig. $5 \mathrm{~g}$ and Fig. $7 \mathrm{~d}$ that the aging strengthening effect will be weakened because part of solute atoms $\mathrm{Zn}$ and $\mathrm{Mg}$ are used by the compound melting balls and crystal separating phase at overheating condition.

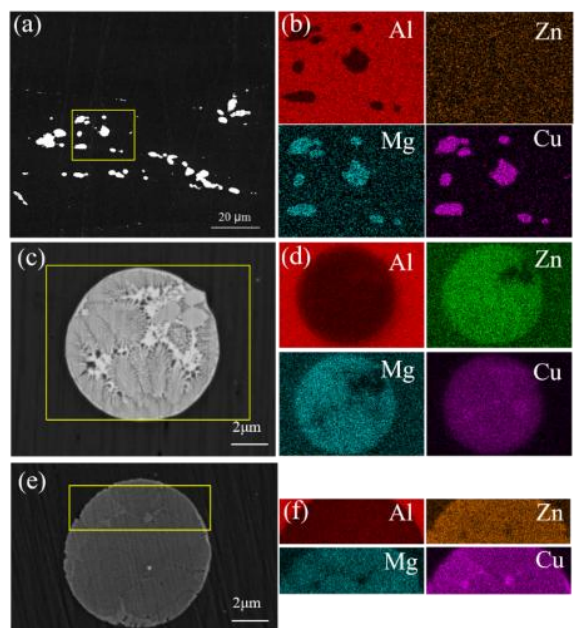

Fig. 4. SEM micrographs and corresponding EDS derived composition maps for $\mathrm{Al}, \mathrm{Zn}, \mathrm{Mg}$ and $\mathrm{Cu}$ of 7050 alloy solution treated at different conditions: (a) (b) $475^{\circ} \mathrm{C} / 3 \mathrm{~h}$, (c) (d) $485^{\circ} \mathrm{C} / 3 \mathrm{~h}$, (e) (f) $500^{\circ} \mathrm{C} / 3 \mathrm{~h}$. 


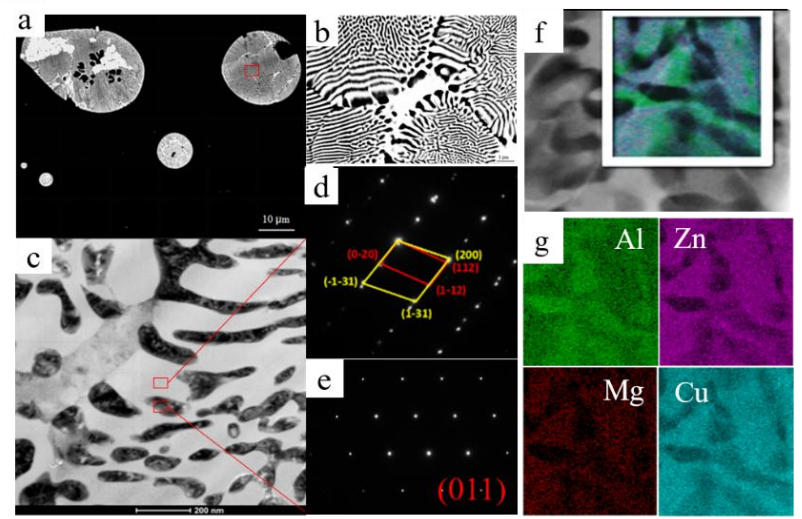

Fig. 5. Microstructure of the compound melting ball of 7050 alloy after solution treated at $500^{\circ} \mathrm{C} / 3 \mathrm{~h}$ : (a) SEM micrograph, (b) high magnification SEM micrograph in (a), (c) TEM bright field image, (d) diffraction pattern of the $\mathrm{S}\left(\mathrm{Al}_{2} \mathrm{CuMg}\right)$ phase projected along [-201], (e) diffraction pattern of the Al matrix taken from the [011] zone axis, (f) STEM image and (g) the corresponding EDS maps.

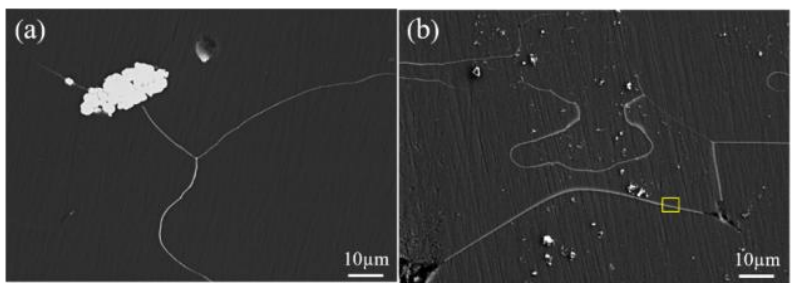

Fig. 6. SEM micrographs of crystal separating phases of 7050 alloy solution treated at different conditions: (a) $485^{\circ} \mathrm{C} / 3 \mathrm{~h}$, (b) $500^{\circ} \mathrm{C} / 3 \mathrm{~h}$.

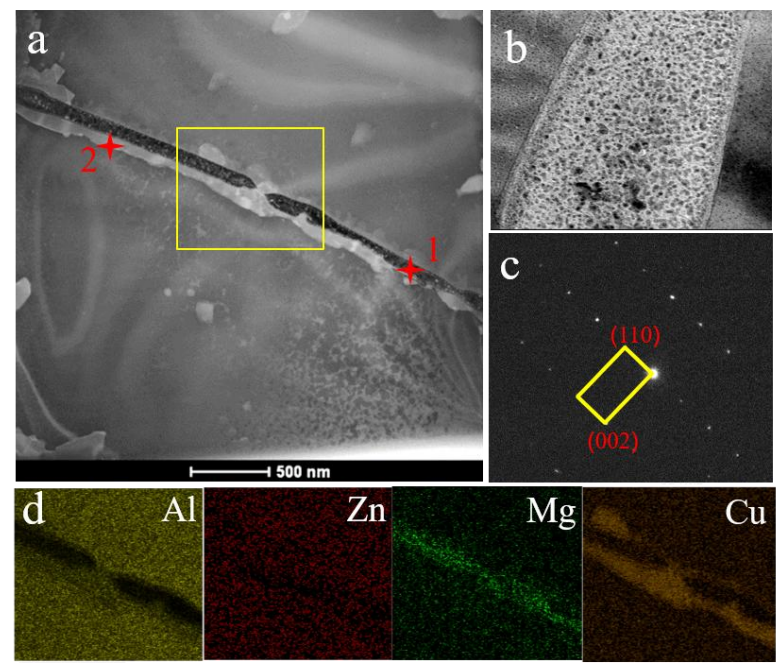

Fig. 7. Microstructure of the crystal separating phases of 7050 alloy after solution treated at $500^{\circ} \mathrm{C} / 3 \mathrm{~h}$ : (a) STEM image, (b) TEM bright field image at the position 1 in (a), (c) diffraction pattern of the $\mathrm{Al}_{2} \mathrm{Cu}$ phase taken from the position 2 marked in (a), (d) the EDS maps of the yellow marked area in (a).

The tensile properties of the peaking aged 7050 aluminum alloy with different solution treatments were carried out and the results are listed in Table 1. It clearly shows that the strength and elongation decrease with the increase of solution temperature. The better ultimate

tensile strength $\left(\sigma_{\mathrm{b}}\right)$, yield strength $\left(\sigma_{0.2}\right)$ and elongation of the alloy solution treated at $475^{\circ} \mathrm{C}$ are obtained as $529.0 \pm 5 \mathrm{MPa}, 479.4 \pm 6 \mathrm{MPa}$ and $8.1 \pm 0.3$, respectively. Fracture surfaces of the peak aging samples with different solution treatments of 7050 aluminum alloy are presented in Fig. 8. For the sample solution treated at $475^{\circ} \mathrm{C} / 3 \mathrm{~h}$, it can be seen from Fig. 8a there are many dimples on the fracture surface, which indicates a ductile fracture. For the $485^{\circ} \mathrm{C} / 3 \mathrm{~h}$ and $500^{\circ} \mathrm{C} / 3 \mathrm{~h}$ samples, a large number of holes can be clearly observed in Fig. $8 \mathrm{~b}$ and Fig. 8c, which are caused by the overheating of constituent particles such as compound melting balls with a large diameter and highlighted with arrows on the fracture surfaces. Generally, the fracture resistance of the 7050 aluminum alloy is very sensitive to the existence of any coarse constituent particles because these sites can act as crack initiation [19]. Additionally, when overheating is significantly worsened, the grain boundaries are also severely weakened because of the crystal separating phase. Thus, the crystal separating phase also adversely affects mechanical properties. It can be concluded from Fig. $5 \mathrm{~g}$ and Fig. $7 \mathrm{~d}$ that the aging strengthening effect will be weakened to some extent because less solute atoms $\mathrm{Zn}$ and $\mathrm{Mg}$ are available at an overheating condition. Hence, compared with solution treatment at $475^{\circ} \mathrm{C} / 3 \mathrm{~h}$, the tensile properties of the peaking aged 7050 aluminum alloy solution treated at $485^{\circ} \mathrm{C} / 3 \mathrm{~h}$ and $500^{\circ} \mathrm{C} / 3 \mathrm{~h}$ are depressed.

Table 1. The tensile properties of the peaking aged 7050 aluminum alloy with different solution treatments.

\begin{tabular}{llll}
\hline Solution & $\sigma_{0.2}(\mathrm{MPa})$ & $\sigma_{\mathrm{b}}(\mathrm{MPa})$ & $\delta(\%)$ \\
temperature & $479.4 \pm 6$ & $529.0 \pm 5$ & $8.1 \pm 0.3$ \\
$475^{\circ} \mathrm{C}, 3 \mathrm{~h}$ & $447.3 \pm 4$ & $503.2 \pm 5$ & $6.6 \pm 0.6$ \\
$485^{\circ} \mathrm{C}, 3 \mathrm{~h}$ & $432.8 \pm 5$ & $485.6 \pm 6$ & $6.1 \pm 0.5$ \\
$500^{\circ} \mathrm{C}, 3 \mathrm{~h}$ &
\end{tabular}

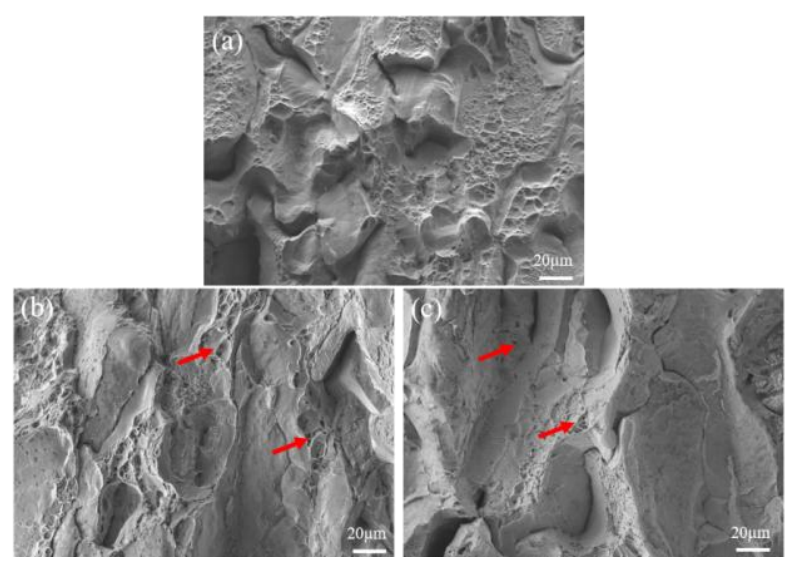

Fig. 8. SEM micrographs of fracture surfaces of the peak aged samples with different solution treatments: (a) $475^{\circ} \mathrm{C} / 3 \mathrm{~h}$, (b) $485^{\circ} \mathrm{C} / 3 \mathrm{~h}$, (c) $500^{\circ} \mathrm{C} / 3 \mathrm{~h}$.

\section{Conclusions}


This study has been performed on the effect of solution temperature on the microstructure and mechanical properties of hot rolled 7050 aluminum alloy plate after subsequent peak aging. The following conclusions may be drawn:

(1) The area fraction of residual phases gradually decreases with the increase of the solution temperature from $475^{\circ} \mathrm{C}$ to $500^{\circ} \mathrm{C}$. However, the overheating phenomenon identified by compound melting ball, crystal separating phase and overheating triangle section was observed at a temperature at $485^{\circ} \mathrm{C}$ or above.

(2) The compound melting ball is composed of $\mathrm{S}\left(\mathrm{Al}_{2} \mathrm{CuMg}\right)$ phase dissolved with $\mathrm{Zn}$ atoms and $\mathrm{Al}$ matrix. The crystal separating phase is consisted of $\mathrm{Al}_{2} \mathrm{Cu}$ phase and the amorphous structure containing solute atom $\mathrm{Mg}$.

(3) The maximum tensile strength of $529 \mathrm{MPa}$ was obtained for the alloy solution treated at $475^{\circ} \mathrm{C}$ for $3 \mathrm{~h}$ followed by peak aging at $120^{\circ} \mathrm{C}$ for $24 \mathrm{~h}$. Overheating will seriously weaken the comprehensive mechanical properties of the alloy.

This work was supported by the Fundamental Research Funds for the Central Universities of China (Grant No. 2018CDGFCL0002 and 2019CDQYWL029), the National Natural Science Foundation of China (Grant No. 51871035), the Foundation for Innovative Research Groups of the National Natural Science Foundation of China (Grant No. 51421001) and the "111" project (B16007) by the Ministry of Education.

\section{References}

1. J.C. Williams, E.A. Starke, Acta Mater. 51 (2003) 5775-5799.

2. F.Y. Xie, X.Y Yan, L. Ding, F. Zhang, S.L. Chen, M.G. Chu, Y.A. Chang, Mater. Sci. and Eng.: A 355(1-2) (2003) 144-153.

3. J. D. Robson, Mater. Sci. and Eng.: A 382(1-2) (2004) 112-121.

4. L.L. Wei, Q.L. Pan, Y.L. Wang, L. Feng, H.F. Huang, J. Mater Eng and Perf 22(9) (2013) 26652672.

5. X.M. Zhang, W.J. Liu, S.D. Liu, M.Z. Zhou, Mater. Sci. and Eng.: A 528(3) (2011) 795-802.

6. N. M. Han, X. M. Zhang, S. D. Liu, D. G. He, R. Zhang, J. Alloys Compd. 509(10) (2011) 41384145 .

7. B. Li, Q.L. Pan, C.P. Chen, H.H. Wu, Z.M. Yin, J. Alloys Compd. 664 (2016) 553-564.

8. Y.L. Deng, L. Wan, Y. Zhang, X.M. Zhang, J. Alloys Compd. 498(1) (2010) 88-94.

9. G.S. Peng, K.H. Chen, S.Y. Chen, H.C. Fang, Mater. Sci. and Eng.: A 641 (2015) 237-241.

10. P.F. Jia, Y.H. Cao, Y.D. Geng, L.Z. He, N. Xiao, J.Z. Cui, Mater. Sci. and Eng.: A 612 (2014) 335342.
11. L. P. Huang, K. H. Chen, S. Li, M. Song, Scripta Mater. 56(4) (2007) 305-308.

12. S.P. Knight, N.Birbilis, B.C. Muddle, A.R. Trueman, S.P. Lynch, Corrosion Sci. 52(12) (2010) 4073-4080.

13. D.K. Xu, N.Birbilis, D.Lashansky, P.A. Rometsch, B.C. Muddle, Corrosion Sci. 53(1) (2011) 217-225.

14. D.K. Xu, P.A. Rometsch, N. Birbilis, Mater. Sci. and Eng.: A 534 (2012) 234-243.

15. D.K. Xu, P.A. Rometsch, N. Birbilis, Mater. Sci. and Eng.: A 534 (2012) 244-252.

16. W.T. Huo, J.T. Shi, L.G. Hou, J.S. Zhang, J. Mater. Process. Technol. 239 (2017) 303-314.

17. F.H. Gao, N.K. Li, N. Tian, Q. Sun, X.D. Liu, G. Zhao, Trans. Nonferr. Met. 18(2) (2008) 321-326.

18. G.S. Wang, Q.Q. Chen, K. Tao, Q.C. Chen, Z.H. Zhao, Mater. Sci. For. 877 (2016) 587-592.

19. P.S. Pao, S.J. Gill, C.R. Feng, Scripta Mater. 43 (2000) 391-396. 